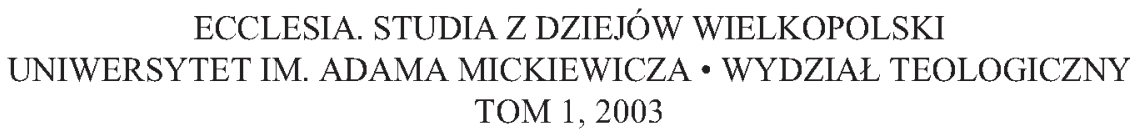

ECCLESIA. STUDIA Z DZIEJÓW WIELKOPOLSKI

UNIWERSYTET IM. ADAMA MICKIEWICZA • WYDZIAL TEOLOGICZNY

TOM 1, 2003

\title{
ANZELM WEISS
}

\section{Filadelfia wielkopolskiego duchowieństwa diecezjalnego z roku 1777}

Duchowieństwo katolickie, zwłaszcza diecezjalne, pozostawało bardzo długo grupa społeczno-zawodowa, stosunkowo najmniej rozpoznawaną przez historyków. Korzystna w tym względzie zmiana nastapiła dopiero w ostatnich dziesięcioleciach. Zapoczątkowały ją badania naukowców związane z Katolickim Uniwersytetem Lubelskim. Wypada wymienić pracowników prowadzących badania w Instytucie Geografii Historycznej Kościoła w Polsce ${ }^{1}$, a także w Instytucie Historii Kościoła na Wydziale Teologii². W tym ostatnim ośrodku, pod kierunkiem ks. prof. dr hab. Zygmunta Zielińskiego, powstało kilka nowatorskich prac doktorskich poświęconych duchowieństwu diecezjalnemu okresu międzywojennego ${ }^{3}$. Powyższą problematykę kontynuują absolwenci KUL w ośrodkach: krakowskim ${ }^{4}$, kieleckim $^{5}$, olsztyńskim ${ }^{6}$. Również w innych centrach naukowych podejmowane są studia nad duchowieństwem 7 . Nie jest moim zadaniem szczegółowe omawianie odnośnej bibliografii.

${ }^{1} \mathrm{~J} . \mathrm{K} 1$ o c z o w s k i. Instytut Geografii Historycznej Kościola w Polsce. Encyklopedia Katolicka (cyt. EK). T. 7. Lublin 1997 kol. 294-295.

${ }^{2}$ J. W a 1 k u s z. Instytut Historii Kościota KUL. Tamże kol. 295-296.

${ }^{3}$ Jedną z pierwszych jest rozprawa Jana W a $1 \mathrm{k} \mathrm{u} \mathrm{s} \mathrm{z} \mathrm{a,} \mathrm{pt.} \mathrm{Duchowieństwo} \mathrm{katolickie} \mathrm{diecezji}$ chetmińskiej. 1918-1939. Pelplin 1992.

${ }^{4}$ Zwłaszcza ks. prof. Jan Kracik. Jego najciekawsza rozprawa na ten temat nosi tytuł: Vix Venerabilis. $Z$ dziejów spolecznych niższego kleru parafialnego $w$ archidiakonacie krakowskim w XVII-XVIII wieku. Kraków 1982 (cyt. K r a c i k. Vix venerabilis).

${ }^{5}$ Zwłaszcza ks. prof. Daniel Olszewski.

${ }^{6} \mathrm{~Np}$. A. K o p i c z k o. Duchowieństwo katolickie diecezji warmińskiej w latach 1525-1821. Cz. 1-2. Olsztyn 2000.

${ }^{7}$ Zob. np. prace A. B a c iń s k i e g o, J. B o r z y s z k o w s k i e g o czy L. B ystrzy ckiego (Duchowieństwo polskie Kościola Rzymsko-katolickiego w Wielkopolsce w latach 1815 1918. Koszalin 1986). 
Wydaje się jednak, że badaczy omawianego problemu tak dla czasów nowożytnych, jak i staropolskich limitują możliwości korzystania z dokumentacji źródłowej. $\mathrm{Ci}$ ostatni są w gorszej sytuacji. Ich bowiem baza archiwalna jest nie tylko uboższa ale i zinstytucjonalizowana. Obraz duchowieństwa okresu staropolskiego kreśli się zazwyczaj na podstawie informacji wydobytych z akt wizytacyjnych lub ustaw synodalnych. Te ostatnie sąźródłami normatywnymi; mają zatem kreować rzeczywistość a nie ją rejestrować. Wizytacje są dokumentami o nieoszacowanej wartości dla historyków różnej specjalności, w tym badaczy problematyki duchowieństwa. Doskonale nadają się do konstruowania statystyk przekrojowych, stanu personalnego, itd. Pozwalają odtworzyć struktury społeczne duchowieństwa, tj. liczebność i pochodzenie terytorialne oraz stanowe (rekrutacje duchowieństwa), wykształcenie i drogi karier kościelnych, moralność, uposażenie ${ }^{8}$.

Niestety wizytacje, podobnie jak i inne źródła epoki staropolskiej, np. akta biskupie, sądowe czy konsystorskie, nie przynoszą informacji dotyczących życia wewnętrznego duchownych. Ich myślenia o sobie jako chrześcijanach mających osiagnąc wieczne zbawienie w niebie. Kapłani bowiem mają być nie tylko głosicielami Słowa, ale mają tym Słowem żyć oraz potwierdzać wiarę i wierność Słowu osobistym przykładem.

Zachowało się bardzo mało informacji na temat troski kapłanów o swoje życie w wymiarze eschatologicznym. Te, nieliczne źródła, którymi dysponujemy zasługują na bliższe poznanie.

Wychodząc z powyższych założeń, pragnę udostępnić tekst książeczki dokumentującej powołanie związku filadelficznego księży wielkopolskiej części diecezji poznańskiej wraz z nazwiskami kapłanów doń należącymi.

\section{Wprowadzenie}

\section{Wyjaśnienie pojęć i terminów}

Termin filadelfia pochodzi od greckiego rzeczownika philadelphia - używanego na określenie miłości wzajemnej między braćmi, czy szerzej między rodzeństwem, w rodzinie. U chrześcijan stał się synonimem miłości jaką powinni się obdarzać nawzajem bracia $^{9}$, wyznawcy wiary w Jezusa Chrystusa i złączeni z Nim w jedno, poprzez Chrzest i Eucharystię ${ }^{10}$. Najpowszechniejszym wyrazem chrześcijańskiej miłości była modlitwa. Przykład modlitwy za uczniów zostawił

\footnotetext{
${ }^{8}$ Przykladem takiego opracowania jest praca S. O $1 \mathrm{c} \mathrm{z}$ a k a. Duchowieństwo parafialne diecezji poznańskiej w końcu XVI i w pierwszej polowie XVII wieku. Lublin 1990.

${ }^{9}$ Zob. Rz. 12, 10; 1 Tes 4, 9-11; Hbr 18, 1; 1 P 1, 22; 2 P 1, 7.

${ }^{10}$ Zob. 1 Kor 10, 16n; Mt 28, 19; Mk 16, 16; Dz 2, 38; Gal 3, 27; Rz 8, 2; 13, 14; Ef 2, 6.
} 
nam sam Chrystus ${ }^{11}$, a apostołowie czesto wzywali do wzajemnej modlitwy ${ }^{12}$. Chrześcijanie rzeczywiście odpowiadali na wezwanie swego Mistrza i Apostołów. Modlitwa wzajemna była częścią chrześcijańskiego kultu pierwszych wieków. Od IV w. praktyce takiej modlitwy zaczęto nadawać zorganizowane formy, które zinstytucjonalizowano w średniowieczu. Nie wdając się w historyczne szczegóły, przytoczę współczesną definicję filadelfii. Zdaniem Krystyny Kuźmak, jest to unia duchowna zawarta pomiędzy osobami moralnymi lub fizycznymi w celu wymiany modlitw i innych dóbr duchowych. W historiografii występuje też filadelfia, jako związek modlitewny, bractwo modlitewne, liga duchowa, unia filadelficzna. Celem głównym zawsze jest wzajemne wspieranie się członków przez modlitwę. ${ }^{13}$ Podobnie określa filadelfię ks. Stanisław Chodyński ${ }^{14}$. Pisze on, że za jego czasów wyraz ten [filadelfia] używa się zwyczajnie do nazwania zakonnych i kaptańskich stowarzyszeń, z celem niesienia sobie duchowej pomocy. Dalej dodaje Modlitwa wzajemna za życia, uczestnictwo w korzyściach z dóbr duchowych i uczynków chrześcijańskiej miłości, spetnianych przez osoby stowarzyszone, szczególnie zaś ofiary Mszy św. i inne modly za zmarlych stanowia glówne punkty ustaw filadelficznych. Dodaje jeszcze Filiadelfia $w$ ściślejszym rozumieniu, znaczy konfraternie kaptańska (confraternitas sacerdotalis $)^{15}$.

Terminologiczne i historyczne wyjaśnienia ks. S. Chodyńskiego przybliżają nas do wydarzeń poznańskich z 1777 roku.

\section{Z dziejów poznańskich bractw i stowarzyszeń kaplańskich}

W diecezji poznańskiej bractwa kapłańskie zawiązały się prawdopodobnie już w XIV w. Pierwsze pisemne wiadomości o nich mamy dopiero z następnego stulecia ${ }^{16}$. Rozwijały się prężnie w naszej i innych diecezjach polskich w XV i XVI wieku. U schyłku XVI w. wiele z nich zanika. Jedne z nich upadły w wyniku przemian gospodarczych i religijnych okresu reformacji, inne połączyły się z bractwami o podobnym charakterze. Zdaniem ks. J. Nowackiego prawdopodobną przyczyną zaniku konfraterni średniowiecznych było lepsze zorganizowanie ducho-

\footnotetext{
${ }^{11}$ Zob. np. modlitwa arcykaplańska Chrystusa w wieczerniku (J 17, 1-26) czy modlitwa za Piotra ( $\mathrm{kk} 22,31-34)$.

${ }^{12}$ Zob., np. Rz 15, 30; Ef 1, 16-19; 1 J 5, 16.

${ }^{13}$ K. K u ź m a k. Filadelfia. Encyklopedia Katolicka. T. 5. Lublin 1989, kol. 183-184.

${ }^{14} \mathrm{~S}$. L i b r o w s k i. Stanistaw Chodyniski. Encyklopedia Katolicka. T. 3. Lublin 1979. kol. 207.

${ }^{15} \mathrm{~S}$. C h o d y ń s k i. Filadelfja. Encyklopedia kościelna. T. 5. Warszawa 1874, s. 347.

${ }^{16}$ J. N o w a c k i. Dzieje archidiecezji poznańskiej. T. 2. Poznań 1964 s. 737-741 (cyt. No w a ck i II) oraz Wojciech R a c z k o w s k i. Konfraternie duchownych w wielkopolskiej cześsi diecezji poznańskiej w okresie przedtrydenckim. (XV-XV w.). Lublin 1966 ss. 150 . Praca magisterska - niestety nie została dotąd opublikowana. Maszynopis w Archiwum Uniwersyteckim KUL.
} 
wieństwa parafialnego w poszczególnych dekanatach poprzez regularnie odbywane kongregacje dekanalne ${ }^{17}$. Wprowadziły je w życie polskie potrydenckie synody prowincjalne i diecezjalne. Obowiązek odbywania zebrań dekanalnych akcentowała stynna Epistola pastoralis B. Maciejowskiego ${ }^{18}$, zalecana na gruncie poznańskim przez bpa Andrzeja Szołdrskiego ${ }^{19}$.

Jak się wydaje na bazie istniejących jednostek terytorialnej organizacji kościelnej narodziły się nowe rodzaje związków pobożnych z udziałem świeckich. Powoływane mogły być do działania wyłącznie za zgodą ordynariusza diecezji lub jego pełnomocnika. Ich status prawny nie jest klarowny. Czy były to konfraternie, stowarzyszenia czy filadelfie, w znaczeniu wyżej podanym? Trudno odpowiedzieć na to pytanie. Nazwy jakie przybierały: unio, sacrum foedus, Tria in unum, sugerują przynależność do kategorii filadelfii. Ale takie określenie nie pojawia się w dokumentach. Trzeba tu wspomnieć, że jedynym źródłem informacji o tych nowych zrzeszeniach kapłańsko-świeckich są wydawane przez same stowarzyszenia druki, w formie książeczek (libelli) ${ }^{20}$, zawierające statuty, spisy członków oraz mniej lub bardziej bogatą część ascetyczna. Książeczki były wydawane tylko dla członków wspólnoty. Dlatego do naszych czasów zachowaly się w śladowej ilości. Wiele z nich nie zostało odnotowanych w Bibliografii Polskiej.

W diecezji poznańskiej, podobnie jak w innych, tworzono wspólnoty dla trzech dekanatów, dopatrując się w wymienionej liczbie szczególnej symboliki. W naszej diecezji najlepiej udokumentowaną unię tworzyły trzy dekanaty archidiakonatu pszczewskiego. Poświadczają to książeczki wydane w 1668, 1707, 1750, 1761 roku. Podobną unię tworzyły dekanaty średzki, pyzdrski i kostrzyński ${ }^{21}$ oraz dekanaty Koźmin, Nowe Miasto i Borek (książeczka z 1761 r.). Bardzo dawną tradycję działań wspólnotowych osób duchownych i świeckich w zakresie troski o sprawy ostateczne człowieka obserwujemy w dekanacie krobskim. Dokumentuje to książeczka wydana przez ks. Stanisława Żarnowieckiego pt. Sprzymierzenie osób duchownych $i$ świeckich [...] na pomoc zupetna $w$ życiu $i$ na ratunek po śmierci (Rawicz 1789).

\footnotetext{
${ }^{17} \mathrm{~N}$ o w a c k i II 741.

${ }^{18}$ S1. N a s i o r o w s k i. List pasterski kard. Bernarda Maciejowskiego. Lublin 1992 s. 117.

${ }^{19}$ M. F ą k a. Synod diecezjalny poznański z roku 1642. W: „Studia Prawno-Historyczne”. Warszawa s. 149-263.

${ }^{20}$ Obszerniej na ten temat mówiłem na dorocznym (4-5. IV. 2002) Zjeździe Wykładowców Historii Kościola w Szczecinie. Powstał z tego art. pt. Konfraternie kaptańskie w XVIII-wiecznej Polsce na przykladzie diecezji poznańskiej (Przegląd źródel drukowanych). Ukaże się w materialach zjazdu przygotowanych do druku przez ks. dr. hab. Jana Walkusza.

${ }^{21}$ O jej ustawach poucza książeczka: Faedus Sacri Vinculi tribus Missarum Sacrificiis obstrictum, ac primo: in Celeberrimo Archidiaconatu Posnaniensi, pro Animabus Confratrum, in tribus Decanatibus, Srodensi, Pyzdrensi, et Kostrzynensi, a multis annis jam olim initum, Toties reimpressum Recenter denuo etc. [brak roku i miejsca wydania]. Informację cyt. za S. C h o d y ń s k i. Filadelfia. s. 357.
} 
Wymienione przykłady świadczą o ożywieniu w drugiej połowie XVIII wieku tendencji do tworzenia różnorodnych wspólnot instytucjonalnych o charakterze korporacyjnym w celach wybitnie ascetycznych. Atmosferze tej ulegali również poznańscy księża.

\section{Narodziny filadelfii i jej charakterystyka}

W 1776 r. na zebraniu dziekanów trzech archidiakonatów diecezji poznańskiej zrodziła się myśl powołania braterskiej filadelfii czyli duchowej wspólnoty wyłącznie kapłanów diecezjalnych z trzech poznańskich archidiakonatów (... in communi saeculares presbyteri tantum per tres praelibatos archidiaconatus, Posnaniensis, Sremensis, et Pscevensis...). Aby jakiejś idei nadać formy prawne, a tym samym możliwości jej realizacji, potrzebny jest człowiek obdarzony darem inwencji i siłą przekonywania. Okazał się nim dziekan dekanatu poznańskiego, ks. Franciszek Grochowski - osoba z urzędu i gorliwości kompetentna, aby nadać ostateczne formy prawne duchowej inicjatywie. Ks. Grochowski to doktor obojga praw, dziekan foralny poznański, notariusz apostolski, prepozyt kolegiaty Najświętszej Maryi Panny in Summo, prymariusz kolegiaty Marii Magdaleny w Poznaniu oraz penitencjarz w katedrze poznańskiej. Był kapłanem głęboko zakorzenionym w poznańskim środowisku Ostrowa Tumskiego. Nie znamy dokładniej jego biogramu. W r. 1772 pełnił funkcję notariusza i w księdze konsystorskiej opisał, jako naoczny świadek, pożar katedry, jaki wydarzył się dnia 17 IX 1772 roku. Relacja została spisana w języku polskim pt. Opisanie nieszczęśliwego przypadku kościola katedralnego poznańskiego ${ }^{22}$.

Tenże duchowny wydał w 1777 r. książeczkę tworzącą wspólnotę filladelfii. $\mathrm{Z}$ deklaracji paktu filadelficznego tam zapisanej (ma tylko dwa punkty) dowiadujemy się że:

1. Każdy uczestnik wspólnoty, powiadomiony, w określony sposób, o śmierci konfratra powinien za jego duszę, możliwe szybko odprawić mszę św.

2. Po śmierci uczestnika wspólnoty filadelficzej, jego następca w urzędzie powinien zapisać się do grona współbraci. Zanim to uczyni ma odprawić mszę św. za swego poprzednika.

Nie były to zbyt wielkie wymagania i jak wolno przypuszczać wielu uczestników konferencji dziekanów oraz inni kapłani zapisali się do tej duchowej unii.

Spis duchownych, którzy zgłosili swoją przynależność do paktu filadelficznego jest interesujący, gdyż podali oni dokładnie swoje tytuły i funkcje. Informacje te mogą być ważne dla wielu historyków - regionalistów, próbujących ustalić listy duchownych i duszpasterzy swoich parafii. Mogą też stanowić bazę danych do innych badań.

${ }^{22} \mathrm{~N} \mathrm{ow}$ a c k i I s. $150-151$. 
W spisie duchownych, uczestników wspólnoty filadelficznej, zapisano 201 nazwisk. Tylko ks. Franciszek Grochowski zapisał się dwukrotnie: raz jako penitencjarz katedry poznańskiej, powtómie, jako dziekan dekanatu poznańskiego. Spis pozwala na dokładne określenie geografii dekanalnego pochodzenia księży. Informacje o tym zawiera tabela:

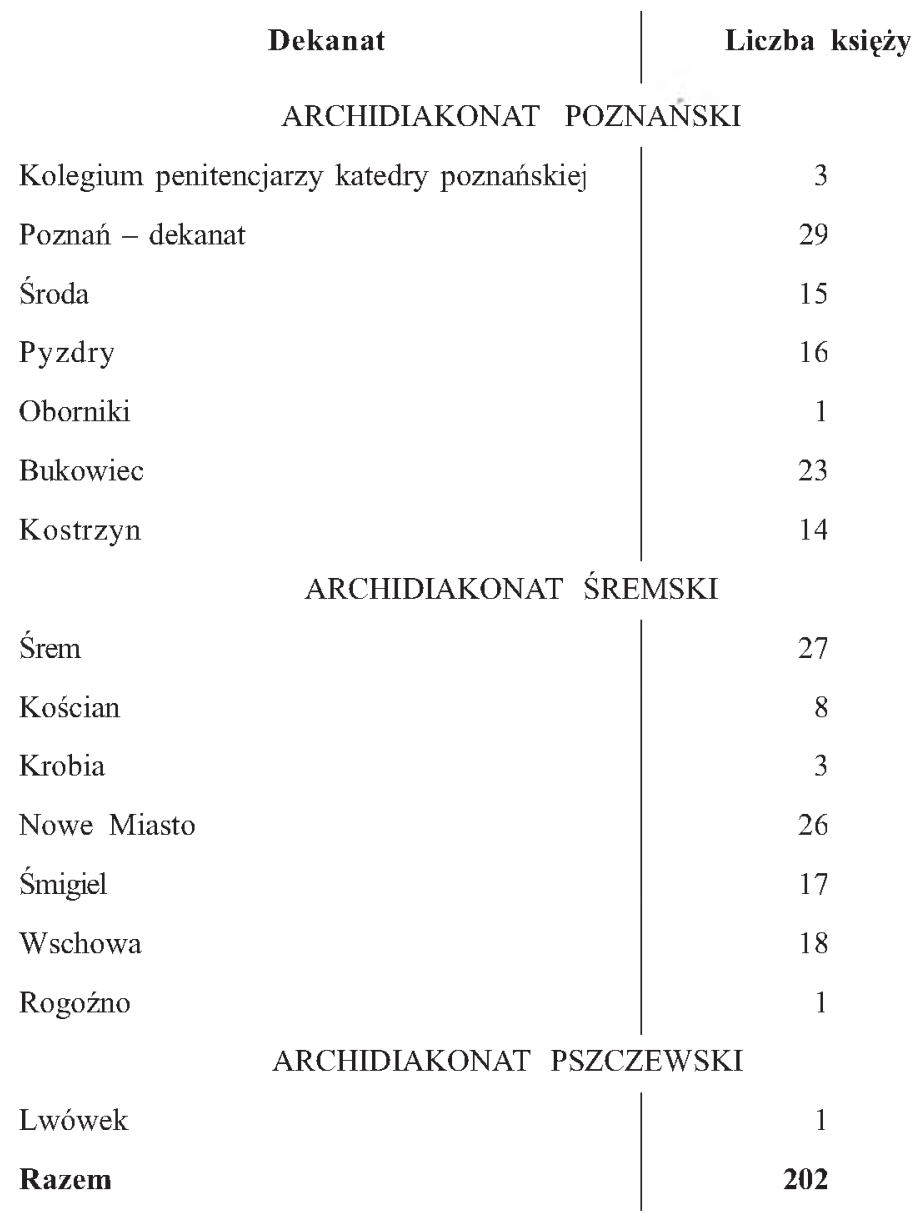

Wśród 201 księży przeważają duchowni mający różnego rodzaju beneficja. Wielu jest też duszpasterzy sprawujących odpowiedzialną funkcję cura animarum oraz 17 księży wikariuszy. Szczególnie rzuca się w oczy brak księży z archidiakonatu pszczewskiego. Nieobecność ich - jak się wydaje - można thumaczyć tym, że na terenie tego archidiakonatu działały od dawna inne, ale o podobnych celach, stowarzyszenia kapłańskie. 


\section{Foto}




\section{Foto}


Foto 


\section{Podstawa i zasady wydania}

Jest nią egzemplarz druku pt. Unio trium archidiaconatuum videlicet Posnaniensis, Sremensis, et Pscevensis... przechowywany w Bibliotece Ojców Paulinów na Jasnej Górze. Druk nie jest notowany w Bibliografii Estreichera. Książeczka została podarowana paulinom, prawdopodobnie przez autora. Taki wniosek nasuwa się z analizy dedykacji: + Bibliothecae Novitiatus ad S. Barbaram Ordinis S. Pauli primi Eremitae 1777. Druk o wymiarach 11 na 18,5 $\mathrm{cm}$, został wydany przez drukarnię Akademii Lubrańskiego, w 1777 roku.

Zawiera następującą treść: adres poświęcony protektorowi dzieła, biskupowi Andrzejowi Stanisławowi Kostce Młodziejowskiemu, ordynariuszowi diecezji i mecenasowi publikacji, ks. Wojciechowi Zakrzewskiemu oficjałowi generalnemu. Następnie zostali wymienieni, jako colendissimi patroni, najważniejsi urzędnicy władz terenowych, tj. archidiakoni i ich koadiutorzy. Pięć stron zajmuje elogium. Potem następuja: Declaratio pacti philadelphici (s. 10-12), Praefatio (s. 13-14). Spis księży mieści się na stronach od 15 do 43 . W części ascetycznej zamieszczono Orationes pro defunctis (s. 44-46) oraz uwagi na temat dobrego przygotowania się do śmierci, zebrane z pism różnych pobożnych autorów (s. 4655). Dziełko zamyka zatwierdzenie władzy diecezjalnej (s. 56).

Pragnę wyjaśnić, że numeracja stron ma charakter wirtualny. Została nadana, wiernie, poszczególnym stronom, po wprowadzeniu tekstu do komputera. Nie ma ich zatem na oryginalnym egzemplarzu. Przy publikacji tekstu starałem się być wierny drukowanemu oryginałowi. Odnosi się to zwłaszcza do stosowania dużych liter oraz kształtu czcionki drukarskiej. W tekście nie ma przypisów, gdyż osoby same się określaja, a zlatynizowane nazwy miejscowości są łatwe do rozszyfrowania.

Strona tytułowa [s. 1]

\section{Edycja tekstu}

UNIO /TRIUM/ ARCHIDIACONATUUM/ Videlicet/ POSNANIENSIS, SREMENSIS, et PSCEVENSIS. /Cum suis distinctis decanatibus/ IN MAJORI POLONIA /sitis,/ IN VIM SPIRITUALIUM/ SUFFRAGIORUM/ Post obitum Confratrum/ per introcontentas Viventium/Personas/ in Sacrificiis Missae /PRESTANDORUM/ piissimo ac aeviterne duraturo /nexu/ OBLIGATA. /POSNANIAE TYPIS ACADEMICIS./ ANNO DOMINI 1777./

[s. 2]

Sub Faustissimis Auspiciis/ Illustrissimi Excellentissimi /ac/ Reverendissimi Domini /Andreae Stanislai Kostka /MŁO D Z I E I O W S K I /EPISCOPI/ POSNANIENSIS et VARSAVIENSIS /SUPPREMI CANCELLARII REGNI /EQUITIS ORDINUM/ Aquilae Albae et S. Stanislai.PROTECTORIS CLEMENTISSIMI. 
Tum

Illustrissimi ac Reverendissimi Domini /ADALBERTI Wyssogotta/ ZAKRZEWSKI /U. J. DOCTORIS/ Custodis Cathedralis, Vicarii in /Spiritualibus, Officialis Generalis Posnaniensis/ Praepositi Bukoviensis, etc.

MECAENATIS FAVENTISSIMI.

[s. 3]

NUNCUPATIO

Illustrissimis ac Reverendissimis DD. in Ecclesia Cathedrali

Posnaniensi ARCHIDIACONIS, Eorumque COADJUTORIBUS.

I.

LEONI MORAWSKI

Metropolit. Gnesn. et Posnan. Archidiacono Officiali Generali Gnesnensi.

FRANCISCO RYDZYNSKI

U. JURIS DOCTORI

Scholastico Gnesn. Praeposito in Chodież, Coadjutori Archidiacono Posnaniensi.

[s. 4]

II.

BOGUSLAO CHLAPOWSKI Utriusque Juris Doctori, Archidiacono Sremensi, Praeposito Ostrorogoviensi.

JOSEPHO Łodzia de Zwonowo ROGALINSKI Sacrae Theologiae et Utriusque Juris Doctori. Coadjutori Archidiacono Sremensi, Praeposito Vschovensi, Universitatis Studiorum Majoris Poloniae Rectori.

III.

ANTONIO UMINSKI Utriusque Juris Doctori Archidiacono Pscevensi, Praeposito Calissiensi. Pro tunc ad Tribunal Regni Judici Deputato.

\section{PATRONIS COLENDISSIMIS.}

[s. 5] Instituti praesentis Opellam, quod Nomini Vestro Illustrissimo inscribendam esse dexerimus Mecaenates Amplissimi, nemini mirum fore videri arbitramur, si Consilii Nostri rationem exploratam habuerit.

Quos enim Pactum isthoc; Patronos impensius exoptare poterat, quam Eos, qui ne dum res sed specie ipsa pietatis Christianae dignitatem sustentare creduntur. Diligens namque rerum Divinarum administratio, sollicita Cultus Divini propagandi cura, salutisque consequendae summa voluntas, satis quemque convincit, quanto res Sacras in pretio habeatis? Quantoque ardore illas augeri cupiatis. Equidem ubi primum singularis morum probitas, perspecta vitae integritas, et rerum fato major prudentia, [s. 6] ac consummata quaedam sapientiae in Vobis eluxit, illico Principes in Dioecesi nostra de- 
creti sunt vobis honores, ut eam prudenti adeo consilio regeretis. Hinc vero quam laeta vobis applaudendi se se offeret materies, qui in ipso maturioris aetatis aditu, ad tantum dignitatis apicem evecti, ut nullam ex illis dotibus aemiseritis, quam cumulum potius omnium virtutum sitis assecuti. Cujus rei vel in praesens etiam sancitum faedus sat evidens argumentum subministrat, quo nihil unquam aut justius, aut saluti animarum providentius excogitari potest. Quid enim nutua illa se se juvandi obligatio? Quid invicem datae repromissiones designant? Si non ardentissimum pietatis studium, atque ferventissimi amoris exemplum evidenter proponunt? Loquitur videlicet illum ipsum fructum tacitae Religionis Vestrae in Deum, et debitae propensionis in proximum, [s. 7] quae non modo lingvis omnium et vocibus celebrabitur, ast etiam isthac significatione in oculos omnium animosque incurret. Quanquam vero parum copiose laudatione hac merita vestra percensemus, date tamen veniam Viri Illustrissimi, et promptam animi nostri voluntatem ratam acceptam habeatis. Enim vero quis commodior erat, aut studii erga Vos nostri contestandi locus, aut quae dignitatis Vestrae amplissimae depraedicandae occasio? Quae a multis temporibus ad nostram hanc usque propagata aetatem, tantae nobilitatis splendore circumfunditur, ut illi ex administratis sapienter Muneribus, ex sub ministratis opportune consiliis, et ex feliciter peractis demandatis officiis, incredibilis exoriatur gloria. Sive enim prima Originis Vestrae incunabula respiciamus, vetustatem ipsam videmur excitasse, sive in praeclarissimum Vestrum Nomen mentes [s. 8] nostras conjicimus, hoc non fidelitatis tantum constantia; sed meritorum insuper magnitudo vehementer commendat. Quae autem Vestrum Ipsorum Viri Illustrissimi dexteritas in agendo? Quae fortitudo in sustinendo, diligentia in pervidendo, qui fervor in urgendo ut res Divina pura semper integra, et incorrupta mente colatur, ut depravatis saeculi hujus vitiorum feracissimi moribus, omnis praecludatur aditus, haud necessarium existimamus isto loco dicere, cum splendide adeo fortiterque gestorum tot adsint testes, quotquot virtuti de trahere nullo modo possunt. Atque ideo jure Officium isthoc, brevis licet elogii, rerum a Vobis talibus tantisque Viris gestarum magnitudo sib vendicat, quae tot, tantaeque sunt, ut male voli potius vitio, qui eas non laudet, carere nequeat, quam assentatoris, qui laudet, suspicione laboret. Quae cum ita sint: felices nos! Quum Vobiscum [s. 9] in partem faederis justissimi venire possimus, tantique Caetus patrocinio praesidioque muniri, qui non patientiae solum in labore et in muneribus obeundis integritatis, verum Religionis in Deum, inque animas suas pietatis domicilium audit. Cujus gloriam si tam honortfice nunc unusquisque jam praedicat, ut prope beatos ob ipsam pacti Religiosi institutionem Vos non dubitet profiteri. Nos qui inter caeteros praestantissimae istius Virtutis propiores testes sumus, et admiratores; patiamini, ut modica ist hac pagella Vobis applaudamus, et novum aliquod Nostrae erga 
vos observantiae monimentum exhibere valeamus Tribuetis illud, ut speramus, tum meritis Vestris, tum promptissimo Nostro in Vos animo, quos omni cum reverentia perpetuo Nos confidite servaturos, videlicet infimos Clientes.

[s. 10]

\section{DECLARATIO PACTI PHILADELPHICI}

Perillustribus et Illustribus Reverendis

Praesens Unio Sacerrimi Pacti Philadelphici, qua nihil salubrius dari, nihil sublimius, nihil sanctiusve excogitari potuit, quam ut in communi Saeculares Presbyteri tantum per tres praelibatos Archidiaconatus, Posnaniensis, Sremensis, et Pscevensis, se ad invicem Suffragiis post decessum e vivis adjuvare valeant ac possint, stabilita est. Proinde itaque sequentes in se continebit Regulas.

\section{[s. 11]}

1mo. Si quem praesenti pacto Philadelphico inscriptum (ut mortalem) e vivis migrare contigerit, illico et sine mora vel DD. Executores demortui, vel Loci Praepositus aut Decanus, dat sibi notitiae de obitu Confratris, via cursoriae certificabit proximiorem Decanatum, hic alterum Decanum, alter vicinos, ut per suos Decanatus quivis Praepositus sive Curatus, sive Commendarius taliter plenam habentes de obitu Confratris notitiam, unum pro anima demortui Confratris absolvat Missae Sacrificium, ac sic per praefatos tres Archidiaconatus quam primum peragatur charitativum demortuo Suffragium.

2do. Ut Congregatio Decanalis horum trium Archidiaconatuum omni triennio ad placitum Perillustrium Decanorum peragatur, necesse est, in qua, locum decessorum e vivis [s. 12] Confratrum, si Successores in Beneficia, occupare voluerint, inscribendi erunt cum clausula hac, ut pro jucundo Spirituali ingressu ad consortium Pacti Philadelphici Confratrum, Missam unam ex nunc pro demortuo Antecessore quilibet illorum legat, et offerat. Et quorum dignissima hoc in Pacto Philadelphico recensentur conscripta Nomina, in illorum etiam post sera facta, Suffragium, unum Sacrificium Missae absolvere tenebuntur dignissimi Confratres.

[s. 13]

\section{PRAEFATIO \\ Ad Perillustres Illustres Admodum Reverendos Confratres}

Sacerrimi Pacti istius Philadelphici Confratres Observandissimi celebratus nuper in Anno elapso Posnaniae; Perillustrium Illustrium Admodum Reverendorum Decanorum ex tribus Archidiaconatubus Posnaniensis, Sremensis, et Pscevensis congressus dudum optatissimum, sed longe ex suo effectu laudatissimum in juvandis suorum Confratrum post decessum Eorum e vivis animabus erexit vinculum, quo obligaremur ad invicem ferre de mortuis Confratribus aeviterne Suf- 
fragia, quia semper duraturum. Et quis tam inhumanus erit ? Quis in immobile vertetur saxum ? Quis e Purgatorii cruciatibus et flammis animas suorum non eripiet Confratrum ? Cum id amor proximi, et dilectio exigit [s. 14] fraterna, attestante S. Gregorio Magno super Psal. 4. Nullum enim est Deo tam gratum sacrificium quam Zelus animarum. Tum Jacobus: 5. v. 16 Orate pro invicem, ut salvemini, multum enim valet deprecatio justi assidua. Act: 2. et Machab. 12. v. 46. Nihil salubrius quam exorare pro defunctis.

Festinate igitur Aestimatissimi Confratres ad Aras Dei in auxilium afflictorum demortuorum Sodalium, Ipsi haec eadem suo tempore recepturi in futurum, occurrite viventes, succurrite decessis, ut illi suo tempore in Patria cum Beatis per vestra elevati Suffragia; possidentes coelestia, nobis ad eandem beatudinem monstrent viam, assistant suis auxiliis, ac recipiant Confratres olim suos, Divinae representaturi Maiestati. Ita precatur: Franciscus Grochowski

Decanus Foraneus Posnaniensis

Author Operis.

[s. 15]

IN ARCHIDIACONATU POSNANIENSI

EX COLLEGIO PAENITENTIARIORUM ECCLESIAE CATHEDRALIS POSNANIENSIS

Illustres Admodum Reverendi

FRANCISCUS GROCHOWSKI U.J.D. Notarius Apostolicus, in Ecclesia Cathedrali Posnaniensi Paenitentiarius.

M. CHRISIANUS THOMAS de JUENGLING Paenitentiarius Cathedralis.

MATHAEUS WOYCIECHOWSKI Paenitentiarius Cathedralis, Ecclesiae S. Laurentii in Chwaliszewo Praepositus.

\section{DECANATUS POSNANIENSIS}

FRANCISCUS GROCHOWSKI U.J.D. Notarius Apostolicus, Collegiatarum B.V.M. in Summo Praepositus, Divae Mariae Magdalenae Posnaniae Primicerius, DECANUS Foraneus Loci.

COLLEGIATA B. M. V. in Summo

illustres Admodum Reverendi

MELCHIOR JANOWSKI Notarius Apostolicus, Illustrissimi Reverendissimi Capituli Cathedralis Posnaniensis Secretarius, Collegiatarum B.V.M. in Summo Custos, et S. Nicolai Canonicus, ibidemque Pater Capituli. [s. 17]

ANDREAS BURGLEWICZ in Alma Universitate Cracoviensis Philosophiae Baccaulareus, B.V.M. Scholasticus, et Divae Mariae Magdalenae Beneficiatus. 
BARTHOLOMAEUS RUTKOWSKI B.V.M. Canonicus, et Divae Mariae Magdalenae Custos.

PAULUS DUSZYNSKI B.V.M. et Divae Mariae Magdalenae Canonicus, Hospitalis S. Crucis Praepositus.

CASIMIRUS BRZRZINSKI B.V.M. Canonicus et Divae Mariae Magdalenae Beneficiatus.

LUCAS METELSKI Vicarius Cathedralis, B.V.M. Canonicus, et S. Barbarae in Chwaliszewo Praepositus.

JOANNES LESKI Ecclesiae Cerekvicensis Curatus.

SIMON TRZEPACZYNSKI B.V.M. Canonicus, et Divae Mariae Magdalenae Beneficiatus.

[s. 18]

COLLEGIATA DIVAE MARIAE MAGDALENAE POSN/ANIAE/

Perillustres Illustres Admodum Reverendi.

MARTINUS KOTARBSKI Praepositus Loci, et Curatus Głuszynensis.

MATHIAS STANISZEWSKI Canonicus.

JOSEPHUS ZAMORSKI Canonicus, Notarus Apostolicus.

JOANNES ZIELENKIEWICZ Canonicus.

STANISLAUS KOSTKA TYMINSKI Canonicus.

MATHIAS NOWICKI Canonicus.

PETRUS ROZEWICZ Beneficiatus.

MATTHAEUS MRUKOWSKI Beneficiatus.

ANTONIUS CYLZDORFF Beneficiatus.

JOANNES CZAYSKE Ecclesiae Ghuszynensis Commendarius. [s. 19]

IGNATIUS RZEPNICKI Beneficiatus.

ECCLESIA PAROCHIALIS S. MARTINI

MICHAEL BRAUZA Praepositus Loci.

ECCLESIA PAROCHIALIS S. ADALBERTI

Admodum Reverendi Domini

ANDREAS NYCZKOWSKI Commendarius.

JOSEPHUS MICHALOWICZ Promotor Confraternitats S. Isidori.

NICOLAUS LIWINSKI Altarista S. Annae.

ECCLESIA PAROCHIALIS S.MARGARETHAE

ET D. PHILIPPI NERII POSNAN/IAE/

illustres Admodum Reverendi

NICOLAUS BAGNOWSKI Praepositus Loci. [s. 20] 
JOANNES ZESŁAWSKI Minister.

ANTONIUS REUTH.

ANTONIUS MILEWSKI.

VALENTIUS KANINSKI.

\section{DECANATUS SREDENSIS}

BNIN

Illustres Admodum Reverendi.

MARTINUS WENCLEWICZ Loci Praepositus, Decanus Foraneus.

GREGORIUS SECULSKI Altarista ejusdem Ecclesiae.

KORNIK

ANTONIUS SŁAWSKI Praepositus Loci.

ANTONIUS DAPINSKI Vicarius Loci.

SPLAWIE

FRANCISCUS STOBIENSKI Curatus Loci. [s. 21]

TULCE

PETRUS ROKOSSOWSKI Curatus Loci.

ECCLESIA COLLEGIATA AC PAROCHIALIS SREDENSIS

Illustres Admodum Reverendi.

THOMAS WĄCHALSKI Decanus.

ANTONIUS STABLEWSKI Custos.

ADALBERTUS MAZUROWICZ Canonicus.

CASIMIRUS BORZECKI Canonicus.

XAVERIUS SMODLIBOWSKI Canonicus et Concionator.

MURZYNOWO

THOMAS JARMUSZKIEWICZ Commendarius.

NIETRZUNOWO

MATHIAS BUCHOLTZ Curatus Loci, Notarius Apostolicus, Assessor Secundus Decanatus Sredensis. [s. 22]

SNIECISKA

FRANCISCUS BRZEZINSKI Curatus Loci, Notarius Decanatus Sredensis.

KOSZUTY

LUDOVICUS KOZLOWSKI Curatus Loci. 


\section{DECANATUS PYZDRENSIS}

Illustres Admodum Reverendi

CIAZZEN

AUGUSTINUS KOLASINSKI Decanus Foraneus, et Praepositus Loci.

WSZEMBOR Z

ADALBERTUS TYLNEROWICZ Curatus Loci.

CZESZEWO

CASIMIRUS SMICINSKI Curatus Loci.

MIŁOSŁAW

VALENTINUS MOLITOWSKI [s. 23] Curatus Loci, Assessor Decanatus.

PAULUS KORTELEWSKI Altarista Literatorum ibidem.

WINNA-GORA

MARTINUS SCHNITT Curatus Loci, Assessor Decanatus.

$$
\text { BARD }
$$

JOANNES STANIEWICZ Curatus Loci.

\section{BIECHOWO}

MICHAEL NABRZEWSKI Praepositus Congregationis S. Philippi Nerii. MARTINUS RYCZKOWSKI.

ADALBERTUS OLSZEWSKI.

$$
\text { KOCZANOWO }
$$

GEORGIUS WAGROWIECKI Curatus Loci, et in Ecclesia Parochiali Vresnensi SS. Rosarii Promotor.

$$
\text { GRBOWO }
$$

STANISLAUS POPIATKIEWICZ [s. 24] Curatus Loci, Secretarius Decanatus.

\section{KOLACZKOWO}

VALENTINUS OTOCKI Curatus Loci.

$$
\text { GOZDOWO }
$$

JOANNES ŁUKOWSKI Curatus Loci.

$$
\text { BIEGANOWO }
$$

PETRUS KORYNSKI Curatus Loci.

SZAMARZEWO

IGNATIUS FREYSZEWICZ Curatus Loci. 


\section{IN DECANATU OBORNICENSI}

CHORYNIA

Illustris Admodum Reverendis JOANNES NEPOMUCENUS Borsa DRZEWIECKI Curatus Loci.

[s. 25]

\section{DECANATUS BUCOVIENSIS}

Illustres Admodum Reverendi.

WIRY

ANASTASIUS PROLEWICZ Decanus Foraneus Bukoviensis, Curatus Virensis.

THEODORUS KORONOWICZ Vicarius Loci.

KONARZEWO

CASIMIRUS LUBIERSKI Secretarius Decanatus, Curatus Loci.

MOSINA

PETRUS Warta KOSICKI Praepositus Loci.

THOMAS RUSZKIEWICZ Vicarius Loci.

STELSZEWO

MATTHAEUS SZCZESNIEWICZ Praepositus Loci, et Praebendarius B.V.M.

IGNATIUS BRUSZCZYNSKI Ecclesiae Szamotulensis Canonicus, Capellanus Loci. [s. 26]

\section{MODRZE}

MARTINUS SKORKOWICZ Custos Decanatus, Vicarius Loci.

SLUPIA

PETRUS TARGOSZYNSKI Curatus Loci.

BUK

Clerus Ecclesiae Bukoviensis.

ADALBERTUS CHWAŁKOWSKI Custos, ac Commendarius Loci, ibidemque Beneficiatus Transfigurationis Christi Domini.

MICHAEL SZCZEPANSKI Concionator Ordinarius cum annexis Beneficiis.

CHRISTOPHORUS BUSZA Capellanus Litteratorum.

STANISLAUS KUJAWSKI Altarista SS. Rosarii et S. Crucis.

THOMAS GROCHOLSKI Altarista S. Josephi et S. Nicolai. [s. 27]

ADALBERTUS TYXICKI Altarista S. Joannis et Mansionarius.

CERADZ

ADALBERTUS JAROCKI Vicarius Loci. 
TARNOWO

MICAEL ZIEMIAKIEWICZ Curatus Loci.

LUSSOWO

ADALBERTUS MIERZEWSKI Curatus Loci.

SKORZEWO

NICOLAUS LIWINSKI Vicarius Loci.

DOPIEWO

IGNATIUS GIECY Curatus Loci, Professor Juris Naturalis et Historiae Sacrae in Scholis Maj. Pol. Posnan. et ad Collegiatam Divae Mariae Magdalenae Beneficiatus.

ANDREAS ISTOLSKI Vicarius Loci. [s. 28]

LUCAS KONOPKA Curatus Loci.

\section{KOMORNIKI}

CASIMIRUS CHARWAZINSKI Vicarius Loci.

\section{DECANATUS KOSTRZYNENSIS \\ KOSTRZYN \\ Illustres Admodum Reverendi.}

BARTHOLOMAEUS SWIERCZYNSKI Decanus Foraneus, et Praepositus Loci.

PETRUS POPRAWSKI Vicarius Loci.

IWNO

CONSTANTINUS ŁAKINSKI Curatus Loci, et Assistens Primus Decanatus.

\section{SIELEC}

MARTINUS SOKOłOWSKI Curatus Loci. [s. 29]

GOŁTOWO

ANTONIUS PATZYKOWSKI Curatus Loci, et Secretarius Decanatus.

NEKLA

ALEXIUS BłACHOWICZ Curatus Loci.

OPATOWKO

JOSEPHUS MARZECHOWSKI Curatus Loci.

TARGOWA-GORKA

MICHAEL KEGELL Curatus Loci, Assistens Secundus Decanatus.

GIECZ

THOMAS PRZYSTANSKI Curatus Loci. 


$$
\text { GRODZISZCZKO }
$$

JOANNES GUZOWSKI Curatus Loci.

CZERLEINO

ADALBERTUS ZMYSłOWSKI Vicarius Loci. [s. 30]

KLESZCZEWO

THOMAS SWIATKOWSKI Commendarius Loci.

SIEKIERKI

IGNATIUS PAULINSKI Curatus Loci.

SWARZEDZ

MICHAEL KOCIEŁKOWSKI Praepositus Loci.

IN ARCHIDIACONATU SREMENSI

DECANATUS SREMENSIS

Illustres Admodum Reverendi

\section{STRZELCE}

Perillustris Admodum Reverendus ROCHUS Leszczyc de Pierzchno [s. 31] KOSZUTSKI Canonicus Gratialis Posnaniensis et Collegiatae Unioviensis Actualis, Praepositus Loci, Decanus Foraneus Sremensis.

JOSEPHUS TYRAKOWSKI S. Annae Capellanus.

JOANNES BUMKIEWICZ Vicarius Loci.

\section{DOMACHOWO}

MELCHIOR POMORSKI Curatus Loci, Notarius Apostolicus, Assessor Decanatus.

\section{GOSTYN}

JACOBUS DROBNICKI Praepositus Loci, Assessor, et Secretarius Decanatus.

MARTINUS ROZKIEWICZ Concionator Ordinarius et S. Rosaliae Capellanus.

MICHAEL TUROMSKI Altarista Literatorum et SS. Corporis Christi.

ANTONIUS BIDERMANSKI S. Annae Capellanus. / s. 32/

LAURENTIUS SMIELKIEWICZ S. Laurentii Capellanus.

\section{SWIERCZYNA}

MATHIAS KEDZIERZYNSKI Curatus Loci, et Cons. Decanatus.

\section{KRZYWIN}

AUGUSTINUS SNOWADZKI Curatus Loci.

STANISLAUS SIELSKI S. Annae Capelanus.

NICOLAUS HINTZ S. Crucis Capellanus. 
MORKA

PAULUS CISZEWSKI Curatus Loci.

ZABNO

JOSEPHUS LESNIEWICZ Curatus Loci.

JASZKOWO

JACOBUS KRUPCZYNSKI Curatus Loci. [s. 33]

SREM

JOSEPHUS PRZYGODZKI Praepositus Loci.

ADALBERTUS PAPALSKI Praepositus S. Spiritus.

ANTONIUS MANKIEWICZ Senior Mansionarius.

THOMAS PROMECKI SS. Corporis Capellanus.

MELCHIOR WOLINSKI S. Josephi Capellanus.

STANISLAUS NOWACKI Litteratorum Capellanus.

DOLSKO

LUDOVICUS FREIER Commendarius.

CASIMIRUS CWOYDZINSKI S. Crucis Capellanus.

JACOBUS PETRYK Vicarius Loci. [s. 34]

KUNOWO

JOSEPHUS LISKOWSKI Curatus Loci.

DECANATUS COSTENSIS.

Illusteres Admodum Reverendi.

CZEMPIEN

MATTHAEUS THADDAEUS CZAPNICKI Praepositus Loci, Decanus Foraneus Costensis.

BłOCISZEWO

PAULUS FLOSIEROWICZ Notarius Apostolicus, Vicedecanus Costensis, Curatus Loci.

GHUCHOWO

MICHAEL KOCIMSKI Secretarius Decanatus. Curator Loci.

WONIESC

JOANNES STANISLAUS KOSTKA SZPECHTOWICZ Curatus Loci. [s. 35]

GRYZYNA

VALENTINUS THADDAEUS SUCHOWSKI Curatus Loci. 
JEłOWIEC

ANTONIUS JANISZEWSKI Curatus Loci.

GOLEMBINO

LAURENTIUS SZARBSKI Curatus Loci.

BIALCZ

JACOBUS MIERZWINSKI Vicarius Loci.

EX DECANATU CROBENSI

ZYTOWIECKO

VALENTINUS WOYTYNSKI Curatus Loci.

MATHAEUS TRAWCZYNSKI Altarista ibidem.

CASIMIRUS BUJAKIEWICZ Vicarius ibidem.

DECANATUS NEOMESTENSIS

Illustres Admodum Reverendi

NOWE-MIASTO

MARTINUS METELSKI Commendarius Loci.

DEBNO

LAURENTIUS WODCZYNSKI Cmommendarius Loci.

BIEZDZIANOW

JOSEPHUS MROWINSKI Curatus Loci.

LGOW

PETRUS PILSKI Curatus Loci.

PAULUS CHYLKOSKI.

POGORZELICA

JOSEPHUS TYMEK Commendarius Loci.

BRZOSTKOW

ANDREAS JOZEFOWICZ Curatus Loci. [s. 37]

ZERKOW

LUCAS JEZIERSKI Praepositus Loci, et S. Nicolai.

MIESZKOW

SWVERINUS SZELISKI Curatus Loci.

WILKOWIA

MATHIAS TYMEK Decanus Foraneus Neomestensis, Curatus Loci, et Cilcen. JOSEPHUS GRZEBIECKI Vicarius Loci. 
SŁAWOSZEW

JOSEPHUS KRZESINSKI Curatua Loci.

LUTYNIA

FRANCISCUS DŁUGOSZ Curatus Loci.

WITASZYCE

MICHAEL KULPICZ Curatus Loci.

GOLENIA

BONAVENTURA KOZŁOWSKI Curatus Loci. [s. 38]

SIEDLEMIN

PETRUS GAZINSKI Curatus Loci.

JAROCIN

JOSEPHUS SIMON WIECKIEWICZ Praepositus Loci.

/_/ MADALINSKI Praepositus Hospitalis S. Spiritus.

GORA

ANTONIUS ROGOZEK Curatus Loci.

PANIENKA

BARTHOLOMAEUS LUZEWSKI Curatus Loci.

CHWALKOW

VALENTINUS MANTEY Curatus Loci.

MCHY

ANTONIUS WOYCIECHOWSKI Curatus Loci.

WLOSCIEIOWKI

JOSEPHUS SLIWINSKI Curatus Loci. [s. 39]

XIĄZ

ANTONIUS KREMSKI Curatus Loci.

ANTONIUS CHAMPELL Vicarius Loci.

GOGOLEW

GASPAR ROZCISZEWSKI Curatus Loci.

DECANATUS SMIGLENSIS

Illustres Admodum Reverendi

LAURENTIUS STAWSKI Decanus Foraneus Smiglensis, Vetero Boianiviensis, Curatus.

CAROLUS CZEPRACKI Litteratorum Altarista et Vicarius. 
JOSEPHUS HINGAROWSKI Altarista SS. Rosarii et S. Josephi Beneficiatus. DYONISIUS BERENT Altarista Immaculatae Conceptionis

Beatae Virginis Mariae. [s. 40]

IGNATIUS REICHSDOR Commendarius Smiglensis, Concionator Germanicus. SVIENTOSLAUS PYSZCZYNSKI Curatus Grobensis.

MARTINUS GEMBIK Curatus Bronicoviensis et Vice-Decanus.

LAURENTIUS SZOLTZ Curatus Radomicensis, Secretarius Decanatus.

ANTONIUS NITSCHE Curatus Mokroviensis.

ADALBERTUS EKIERTOWICZ Curatus Goniembicensis Cong/regationis/ Notarius.

NICOLAUS KANKIEWICZ Curatus Kąkoleviensis.

OSIECZNA

JOSEPHUS MATCZYNSKI Praepositus Loci.

GEORGIUS FENGLER Litteratorum Promotor.

VALENTINUS PYSZCZYNSKI Mansonarius. [s. 41]

FRANCISCUS WILNIEWICZ Mansionarius.

BOGUSLAUS HINCZEWSKI Curatus Czervonoviensis.

BARTHOLONAEUS BIAŁOSZEWSKI Curatus Drzeszkoviensis, Assessor.

DECANATUS VSCHOVENSIS

Illustres Admodum Reverendi.

MATTHAEUS GRYGIER Decanus Foraneus Vschovensis, Praepositus Swięciechviensis.

FRANCISCUS WOYNAROWICZ Canonicus Varsaviensis, Vice-Decanus Vschovensis, Curatus Bukoviecensis.

FRANCISCUS ENGELL Secretarius Decanatus Vschovensis, Curatus Vilkoviensis.

ANTONIUS GRYGIER Coadjutor Praepositi Swięciechoviensis [s. 42]

ANTONIUS SCHULTZ SS. Rosarii Promotor ibidem.

JOANNES KOCH Curatus Dembołołecensis.

MATHIAS FENGLER Curatus Zbarzeviensis.

FRANCISCUS HOFFMAN Commendarius Vschovensis.

ANTONIUS FENGLER Curatus Łysinensis.

JOSEPHUS BREITSCHNEIDER Curatus Liginensis.

JOSEPHUS WEYSS Curatus Smieszkoviensis.

JOSEPHUS KOLCZYCKI Vicarius Brennensis.

SIMON SZYDEOWSKI Curatus Włoszakoviensis.

STEPHANUS PAWELSKI Vicarius ibidem.

THOMAS STANIEWICZ Canonicus Gratialis, Praepositus

Dłuszynensis. [s. 43] 
CLEMENS OFFIARKIEWICZ Vicarius ibidem.

FRANCISCUS STAWSKI Curatus Krzcycensis.

BENIAMIN ERBSMAN Curatus Gołanicensis.

EX DECANATU ROGOZINENSI

DLUGOGOSLINA

Admodum Reverendus ANTONIUS DORPOWICZ Notarius Decanatus, Curatus Loci.

\title{
IN ARCHIDIACONATU PSCEVENSI \\ EX DECANATU LVOVECENSI
}

Admodum Reverendus STANISLAUS KWASNIEWSKI Curatus Łescensis. [s. 44]

\section{ORATIONES PRO DEFUNCTIS}

Post Missam Defunctorum dicendae

Fidelissime, ac piissime Domine JESU ex vulneribus Tuis, et misericordissimo corde tuo, omnibus Fidelibus Defunctis refrigerium largire. Memor esto Benignissime JESU misericordiarum Tuarum, quae a saeculo sunt, et fidelibus defunctis da requiem sempiternam ; descendat Pie JESU Sangvinis Tui rosei effusio in Purgatorium, recreet et refrigeret omnes ibi captivos, et patientes ; libera eos Domine DEUS Noster; ex omnibus angustiis Eorum. Domine JESU ego do illis mortem [s. 45] Tuam, et sangvinem Tuum. Quomodo enim illis aliter possum succurrere, aut mederi : Largiro sic, ut virtute horum liberentur. Amen.

Requiescant in pace. Resp. Amen.

\begin{abstract}
Alia
Avete omnes fideles, det vobis requiem Ille, qui est vera Requies JESUS Christus Filius Dei vivi, qui natus est de Immaculata Virgine MARIA, pro nostra omniumque salute, et vos redemit suo prtioso sangvine, benedicat vos, et a paenis liberet, faciatque vos resurgere in die Resurrectionis, et Angelis suis associare, ac in Caelis secum sine fine gaudere. Amen.

Hanc Orationem composuit Joannes XXII. Papa, concedens cuilibet [s. 46] Caemeterium sive Ecclesiam transeunti, et eandem dicenti, tot dierum Indulgentias, quot Christi fidelium Corpora ibi sepulta sunt.
\end{abstract}




\section{OBSERVANDA TEMPORE INSTANTIS ULTIMI VITAE, COLLECTA EX PIIS ASCETIS}

I.

Intellecto mortis periculo, quam primum pete Sacramenta Poenitentiae, Eucharistiae ac Extremae Unctionis, et applicationem Indulgentiarum: cum majori enim fructu sumuntur Sacramenta a viatore, rationis usu, et integris pollent viribus. Et hoc etiam juvabit, cum Sacerdote praesente pactum facere, ut te sensibus destitutum in in ultimo vitae articulo ultimate absolvat. S. Laurentius Justinianus sumpto Viatico dixit: Suscipe me Bone Jesu [s. 47] viata et salus animae meae: illa, ego ovis amista, ad Te Pastorem redeo, ac peto Domine, ut ad ovile Tuum me reducas, portio creaturae Tuae postulat micas svavissimae mensae Tuae. Postea ad circumstantes dixit: Vos interea Socii Dilectissimi servate Dei Praecepta: Omnis caro faenum, et omnis gloria eius tanquam flos faeni. Contemplamini me, ecce arui ut faenum et flos eius decidit, mihi credite, nihil est praestantius, quam amare Deum.

II.

Si cui facienda est restitutio famae, fortunae, fiat adhuc te vivente, si fieri potest: alioqin ut quamprimum post mortem tuam fiat, efficaciter provide: ob quod testamentum securius. Mori male times, et male vivere non times, corrige male vivere, time male mori, sed noli [s. 48] timere, non potest male mori, qui bene vixit. S. Augustinus.

III.

Condona ex amore Christi mansvetissimi, omnes injurias, offensas etiam justas tuis inimicis, ut DEUS tibi peccata condonet, juxta: Et dimitte debita nostra etc. neque cadat post Fata illud: Pejores morimur, quam nascimur.

\section{IV.}

Pete veniam publice pro defectibus, et si dispositio bonorum facienda est, absque mora fiat, ut monet D. Augustinus: Dum sapiens es, dum tuus es. Fiat in statu gratiae, prius Bona animi, Bona Corporis, post Bona Fortunae, quam ornatissime juxtu proportionem status, conditionis tuae omnia. Svaviter dispone: Pauper ut requiescat moritur, dives ut crucietur, juxta illud: Potentes, potenter tormenta patientur.

V.

Potes dare pium aliquod monitum Consangvineis, servis et caetera. Ita S. Ludovicus Rex Galliarum moribundus, Filio suo dicebat: Fili mi in eam rem ante omnia incumbe, ne unquam peccatum mortiferum committas. 
S. Antonius Magnus haec verba ad Fratres dixit: Ad JESUM suspirate, et hoc sanctissimum Nomen vestris figite mentibus.

Hugo de S. Victore haec semper optare docuit: Ut cibus ultimus sit SS Eucharistia, ut extrema cogitatio sit de Passione Christi. Ut ultimum verbum sit Dulcissimum Nomen JESU. Ad quod excitandum, poterit ab aliquo legi Passio Domini, vel piae morientium historiae.

VI.

Poterit interim moribundus has facere intentiones, pro sua morte saltem corde: volo mori, quia amo [s. 50] DEUM, et ideo exnunc volo illi ita statuenti obedire. Volo mori, ut nunquam deinceps DEUM offendam. Volo mori, ut DEUM coram videam, et perfectius amem cum Dulcissima MARIA, sanctisque Patronis meis. Volo mori, ut imiter JESUM et MARIAM morientem. Volo mori, ut immoler DEO, cui me tot modis debeo. Volo mori, ut vivam in Caelo in aeternum.

VII.

Armetur aeger in hoc supremo conflictu, Instrumentis, Pietatis, Imagine Christi Crucifixi, Sacris Reliquiis, et Imaginibus Sanctorum, quas identidem adoret, et osculetur. Item Cereo benedicto, quem manibus tenens agat DEO gratias, quod se vacaverit in admirabile lumen suum, dicatque: Tu illuminas lucernam meam, Domine, illumina tenebras meas, illumina oculos meos, ne unquam [s. 51] obdormiam in morte, ne quando dicat inimicus meus, praevalui adversus eum.

Aqua lustrali aspergens dicat: Exurgat Deus et dissipentur inimici ejus, et fugiant qui oderunt eum a facie ejus.

VIII.

Faciat moribundus has vel illas protestationes: Protestor quod morior verus Catholicus in Fide, Spe, et Charitate in DEUM. Protestor quod volo mori mancipium JESU et MARIAE. Protestor quod exnunc et pro reliquo vitae tempore nolo consentire ulli tentationi Daemonis. Confirmo Fidem datam DEO in Baptismo, et abrenuntio mundo, carni, sathanae, meque Tibi coniungo Christe in tempore et aeternitate. Protestor quod libenter accepto omnem dispositionem, tam circa animam meam; quam circa corpus post mortem meam. [s. 52]

IX.

Ad extremum breviter eliciat Actus Virtutum Fidei, Spei, Charitatis, Contritionis desiderii videndi Deum.

Credo Domine, spero Domine, amo Te Deus meus misericordia mea. Mihi vivere et mori lucrum. Ostende Te mihi Consolator meus, videam Te Lumen oculorum meorum, veni Gaudium spiritus mei, videam Te laetitia cordis mei. Amplector Te Bonum sine quo nihil est bonum. Fruar Te Optimo, sine quo nihil est opti- 
mum, o vita cui omnia vivunt, Vita; quae es mea vita, per quam vivo, sine qua morior vita vitalis, Dulcis, et Amabilis ubi quaesto es? Ubi Te inveniam, ut in $\mathrm{Te}$ deficiam, et in Te subsistam. Eja Domine, moriar ut Te videam, et hic moriar: etiam mori desidero ut videam Christum, vivere renuo, ut [s. 53] vivam cum Christo. Adjuva Domine creaturam tuam, ne pereat in malitia sua, quod operata est Bonitas Tua, o Fins vitae, vena aquarum viventium, quando veniam ad aquas dulcednis Tuae de terra deserta invia, et inaquosa, o Dies praeclara et puchra nesciens vesperum, non habens occasum, in qua audiam: Intra in Gaudium Domini Tui, ubi erit omne bonum, et non erit aliquod malum: ubi erit quidquid voles, et non erit quidquid noles veni Domine, et noli tradere, veni Domine JESU, visita me in pace, veni et educ vinctum e carcere putridae carnis meae.

\section{$\mathrm{X}$.}

Tandem jamjam ultimo moriens, alloquere Jesum his affectibus quam tenerrime. Jesus Maria Amores mei moriar amore Vestri, o Jesu, esto mihi Jesus, et Salvator. [s. 54] Jesu: agonizans morti Tuae mortem meam unio: Jesu pro me mortue, mors tua sit vita mea, o Bone Jesu intra vulnera Tua absconde me. Domine Jesu suscipe spiritum meum, Tu es Christus Filius Dei vivi, Dominus meus et Deus meus.

Hic osculando vulnera Crucifixi dic:

Ad pedes: Salvete Domini nostri Jesu Christi pedes adorandi tot itineribus fatigati, Magdalenae lacrymis loti, pro me clavis in Cruce confixi: Haec requies mea in saeculum saeculi, hic habitabo, quoniam elegi eam.

Post ad Manus osculando: Salvete adorandae Domini nostri Jesu Christi Manus: in Cruce pro me extensae, et clavis confixae; semper apertae, ut impleatis omnem animam benedictione; Haec requies mea in saeculum saeculi, hic habitabo, quoniam elegi eam.

Ad vulneratum [s. 55] Domini Latus; intingendo cor, animam tuam in illo dic: Salve Latus gloriosum Domini nostri JESU Christi, pro me lancea militis perforatum. Haec requies mea, etc.

Ad Caput sic dices: Salve tremendum cunctis potestatibus Caput JESU Christi Salvatoris Nostri, pro me arundine percussum, et spinis coronatum. Haec requies etc.

Ad totum dulcissimum Corpus cum ingenti affectu dices: Salve venerandum Corpus Christi JESU, pro me in Cruce suspensum, vulneratum, mortuum, et in sinum Sanctissimae Matris Tuae depositum. Haec requies mea in saeculum saeculi, hic habitabo, quoniam elegi eam.

O JESU mi in manus tuas reddo spiritum meum. JESUS, JESUS, JESUS meus. DEUS meus et omnia. 
[s. 56]

\section{APPROBATIO DIAECESANA}

Cum ex S. Scripturae textu clare cuique constare non dubitem; quam sit: Sancta et salubris cogitatio exorare pro defunctis; hinc pia desiderio; Personarum Spiritualium in trinis introcontentis Archidiaconatibus specificarum, mutua sibi post obitum praestandi pietatis suffragia in isthoc Libello unanimi Voto, sive pacto certo et aeviterne duraturo obligata, opus fore pientissimum censeo, quod quidem Opus cum vel maxime studio ac solicitudine sua Perillustris Admodum Reverendus FRANCISCUS GROCHOWSKI utpote prior ordine intra Archidiaconatus praefatos DECANUS Foraneus Posnaniensis jam pro pietate et chariatae mutua in dignissimos Confratres suos, jam pro exemplari munere suo Decanali luci publicae exponendum curaret, cumque nihil fidei Catholicae bonisque dissonum moribus exinde eveniat opportunam proinde ad eum effectum facultatem concedo.

Die 13. Augusti. Anno 1777.

M. FRANCISCUS MINOCKI U.J.D. et Profesor, Academiae Posnaniensis RECTOR, in Diaecesi Posnaniensi Librorum CENSOR. mpp. 
